\title{
The impact of the systemic inflammatory response on hepatic bacterial elimination in experimental abdominal sepsis
}

Katja Hanslin ${ }^{1}$, Jan Sjölin ${ }^{2}$, Paul Skorup ${ }^{2}$, Frida Wilske ${ }^{2}$, Robert Frithiof ${ }^{3}$, Anders Larsson ${ }^{4}$, Markus Castegren ${ }^{2,5}$, Eva Tano ${ }^{6}$ and Miklos Lipcsey ${ }^{3^{*}}$ (i)

* Correspondence: miklos.lipcsey@ surgsci.uu.se

${ }^{3}$ Hedenstierna Laboratory, CIRRUS, Anesthesiology and Intensive Care, Department of Surgical Sciences, Uppsala University, Uppsala, Sweden

Full list of author information is available at the end of the article

\section{Abstract}

Background: Bacterial translocation from the gut has been suggested to induce a systemic inflammatory response syndrome (SIRS) and organ dysfunction. The liver has a pivotal role in eliminating circulating bacteria entering from the gut. We investigated whether pre-existing inflammation affects hepatic bacterial elimination.

Methods: Fifteen anaesthetised piglets were infused with E. coli in the portal vein for $3 \mathrm{~h}$. The naive group $(n=6)$ received the bacterial infusion without endotoxin exposure. SIRS (SIRS group, $n=6$ ) was induced by endotoxin infusion $24 \mathrm{~h}$ before the bacterial infusion. For effects of anaesthesia, controls $(n=3)$ received saline instead of endotoxin for $24 \mathrm{~h}$. Bacterial counts and endotoxin levels in the portal and hepatic veins were analysed during bacterial infusion.

Results: The bacterial killing rate was higher in the naive group compared with the SIRS group $(p=0.001)$. The ratio of hepatic to portal venous bacterial counts, i.e. the median bacterial influx from the splanchnic circulation, was 0.06 (IQR 0.01-0.11) in the naive group and $0.71(0.03-1.77)$ in the SIRS group at $3 \mathrm{~h}$, and a magnitude lower in the naive group during bacteraemia $(p=0.03)$. Similar results were seen for hepatic endotoxin elimination. Peak log tumour necrosis factor alpha was higher in the naive 4.84 (4.77-4.89) vs. the SIRS group $3.27(3.26-3.32) \mathrm{mg} / \mathrm{L}(p<0.001)$.

Conclusions: Our results suggest that hepatic bacterial and endotoxin elimination is impaired in pigs with pre-existing SIRS while the inflammatory response to bacterial infusion is diminished. If similar mechanisms operate in human critical illness, the hepatic elimination of bacteria from the gut could be impaired by SIRS.

Keywords: Sepsis, Mononuclear phagocyte system, Escherichia coli, Endotoxins, Bacterial translocation, Animal models

\section{Background}

The liver is an essential organ involved in the elimination of bacteria and bacterial products from the circulation and houses a substantial part of the mononuclear phagocyte system (MPS) implicated in this process. The human gastrointestinal tract houses several trillion microbial cells [1] crucial to normal functioning of the body but is also capable of causing severe infections. The liver is exposed to intestinal microorganisms and microbial fragments termed pathogen-associated molecular patterns (PAMPs) via the portal vein. Under healthy conditions, the liver acts as a gatekeeper preventing

(c) The Author(s). 2019 Open Access This article is distributed under the terms of the Creative Commons Attribution 4.0 International License (http://creativecommons.org/licenses/by/4.0/), which permits unrestricted use, distribution, and reproduction in any medium, provided you give appropriate credit to the original author(s) and the source, provide a link to the Creative Commons license, and indicate if changes were made. 
inflammatory triggers (e.g. bacteria and endotoxin) from entering the systemic circulation [2]. Kupffer cells, the resident macrophages in the liver, efficiently phagocytise pathogens and PAMPs entering the liver through the arterial or portal circulation or through both [3].

Bacterial translocation, defined as migration of viable bacteria or bacterial products from the gut lumen to normally sterile tissues [4], has been suggested to induce and maintain the systemic inflammatory response syndrome (SIRS) and multiple organ dysfunction syndrome (MODS) [5, 6], as well as serve as a source for bacterial infections [7]. While it is a matter of debate in sepsis and trauma, bacterial translocation has been described in liver cirrhosis [8] and in patients with intestinal obstruction [9]. In surgical patients, bacterial translocation is associated with systemic infectious complications [7, 10-12] and loss of gut barrier function may contribute to the development of MODS [13, 14]. Whether PAMPs entering the portal vein reach the systemic circulation depends on the barrier function of the liver, and although translocation of bacteria and PAMPs in severe illness has been extensively investigated, data on the barrier function of the liver are scarce.

The evidence on the development of immunosuppression and decreased bacterial clearance in sepsis is convincing [15-19]. We hypothesised that immunosuppression due to SIRS might also lead to depressed function in the hepatic MPS and thus to increased bacterial influx to the systemic circulation and subsequent escalated inflammation, assuming that bacterial translocation from the gut occurs in systemic inflammation.

The primary aim of the study was to investigate bacterial and endotoxin influx from the gut during bacteraemia to the systemic circulation in healthy piglets compared with piglets with pre-existing SIRS. Our primary endpoint was to study bacterial elimination by the liver during an infusion of live Escherichia coli (E. coli), measured as the ratio of hepatic to portal vein bacterial counts. Secondary aims were to investigate the hepatic elimination of endotoxin and the inflammatory response elicited by the $E$. coli infusion.

\section{Materials and methods}

\section{Ethics statements}

The experiment was approved by the Animal Ethics Board in Uppsala, Sweden (Dnr. C150/14). The piglets were handled in accordance with the Guide for the Care and Use of Laboratory Animals (EU Directive 2010/63/EU). ARRIVE and MQTiPSS guidelines were followed when relevant for these experiments [20, 21]. Some ARRIVE recommendations have been described by us previously and are not reported here [22]. MQTiPSS recommendations on replication and comparison of experiments in other animal with regard to species, comorbidities or sex were not performed for practical reasons. Neither was organ failure score or antimicrobial therapy used due to the nature and design of the experiments.

\section{Protocol}

Fifteen Norwegian landrace breed piglets of both sexes, 8-10 weeks old, were anaesthetised and then catheterised for monitoring as described in Additional file 1: Supplement file. The animals were randomly assigned in blocks by blinded allocation to three experimental groups: naive $(n=6)$, SIRS $(n=6)$ and controls $(n=3)$. The study design is depicted in Fig. 1. 


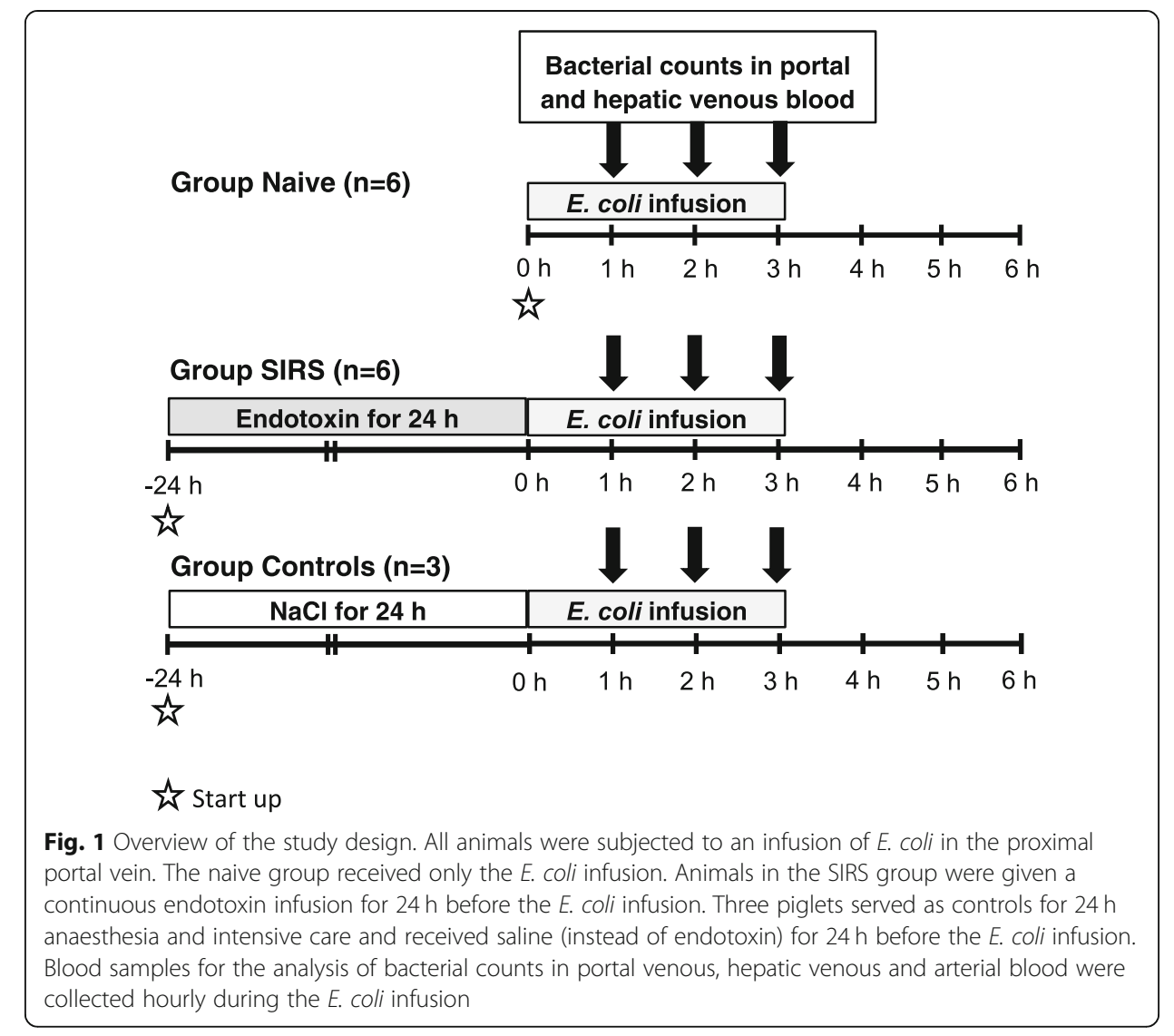

The E. coli (B09-11822 serotype O-rough:K1:H7; Statens Seruminstitut, Copenhagen, Denmark) used is a clinical isolate that is serum resistant and encapsulated. Fresh subcultures were prepared and grown into logarithmic growth phase before the experiment. To mimic bacterial influx from the gut $E$. coli, a common gut pathogen was infused into the portal vein. The microbiological methods were described previously [23]. In short, all animals were exposed to a continuous infusion of live E. coli $\left(5 \times 10^{8}\right.$ colony-forming units [CFUs] in $25 \mathrm{~mL}$ saline) in the portal vein through the proximal catheter tip for $3 \mathrm{~h}$.

To induce a mild SIRS, the animals in the SIRS group were exposed to intravenous endotoxin (Escherichia coli: 0111:B4; Sigma Chemical, St. Louis, MO) at $0.063 \mu \mathrm{g} \times \mathrm{kg}^{-1} \times \mathrm{h}^{-1}$ [24] for $24 \mathrm{~h}$ before the E. coli infusion. The animals in the control group, who received saline instead of endotoxin before the start of the bacterial infusion, served as controls for the effects of $24 \mathrm{~h}$ of anaesthesia. All animals were followed for $3 \mathrm{~h}$ after completed E. coli infusion.

During the E. coli infusion, simultaneous blood samples for bacterial counts were taken hourly from the portal vein through the distal catheter tip, the hepatic vein and the artery. Bacterial concentrations were corrected for the weight of the animals and the infused E. coli dose. Bacterial counts during bacteraemia were determined by plating $0.1 \mathrm{~mL}$ blood in triplicate from the portal vein, hepatic vein and artery. E. coli was identified by colony morphology. To determine the pig blood bactericidal capacity, blood collected at $0 \mathrm{~h}$ was inoculated ex vivo with $10^{5} \mathrm{CFU} \times \mathrm{mL}^{-1} E$. coli in duplicate at $37^{\circ} \mathrm{C}$. Viable counts were plated hourly for $6 \mathrm{~h}$. Bacteria-free endotoxin was analysed in plasma from the portal and hepatic vein at start-up in the SIRS and control group 
and at 0 and $3 \mathrm{~h}$ in all groups. Arterial blood was analysed regularly for blood gases, tumour necrosis factor-alpha (TNF- $\alpha$ ), interleukin 6 (IL-6), interleukin 10 (IL-10) and complement. Immunosuppression was measured using the IL-10/TNF- $\alpha$ ratio [19, 25]. Complement activation was assessed with soluble TCC (sC5b-9).

The animals were treated according to a protocol to maintain vital parameters within pre-set limits (Additional file 1: Table S1). In short, arterial pressure of oxygen $\left(\mathrm{PaO}_{2}\right)$ was maintained at $>10 \mathrm{kPa}, \mathrm{MAP}$ at $\geq 60 \mathrm{mmHg}$ and cardiac output $(\mathrm{CO})$ at $\geq 2 \mathrm{~L} \times \mathrm{min}^{-1}$. At the end of the experiment, all animals were culled by i.v. exposure to potassium chloride.

\section{Measurements}

From $0 \mathrm{~h}$, mean arterial pressure (MAP), mean pulmonary arterial pressure (MPAP), central venous pressure (CVP) and heart rate (HR) were continuously monitored. CO was measured with a Swan-Ganz catheter. Airway pressure values and respiratory volumes were recorded from ventilator readings. All physiological data were registered at intervals predetermined in the experimental protocol. Creatinine clearance was calculated by the conventional formula [26].

Blood from a cervical artery, pulmonary artery and hepatic vein were analysed for $\mathrm{pH}$, gas tensions $\left(\mathrm{PaO}_{2}, \mathrm{PaCO}_{2}\right)$, oxygen saturation, lactate, base excess and haemoglobin on an $\mathrm{ABL}^{\mathrm{TM}} 800$ and a Hemoximeter ${ }^{\mathrm{TM}}$ OSM-3 (Radiometer, Brønhøj, Denmark). Full blood count was analysed on a CELLDYN Sapphire (Abbott Scandinavia, Kista, Sweden). Plasma endotoxin was analysed in heparinised plasma with the chromogenic limulus amebocyte lysate assay (Endochrome-K; Charles River Endosafe, Charleston, SC, USA), and the lower detection limit in plasma was $<0.05 \mathrm{EU} \times \mathrm{mL}^{-1}$. Plasma TNF- $\alpha$ and IL- 6 were measured with porcine-specific sandwich enzyme-linked immunosorbent assays (ELISA; DY690B [TNF- $\alpha$ ], DY686 [IL-6] and DY693B [IL-10], R\&D Systems, Minneapolis, MN, USA). The limit of detection (LOD) in EDTA plasma was $<60 \mathrm{pg} / \mathrm{mL}$ for both TNF- $\alpha$ and IL-6. The LOD for IL-10 was $25 \mathrm{pg} / \mathrm{mL}$. The ELISAs had total coefficients of variation of approximately $6 \%$. Creatinine in urine and plasma was measured with enzymatic creatinine reagents (8 L24, Abbott Laboratories, Abbott Park, IL, USA) on a BS380 instrument (Mindray, Shenzhen, China).

For sC5-9 measurement, anti-Human C5b-9 (Diatec 5010; Diatec AS, Oslo, Norway) was used to capture antibody in sandwich ELISA [27]. Samples and calibrators were added to the wells. Bound sC5-9 was detected by biotinylated anti-C6 monoclonal antibody (Quidel, San Diego, CA, USA) and Streptavidin-HRP. The LOD for sC5-9 was $300 \mathrm{AU} / \mathrm{L}$.

\section{Measurement of hepatic function}

In a pilot study with the same set-up, hepatic function was assessed in 12 piglets by measuring indocyanine green (ICG) disappearance rate (ICG-PDR) [28].

\section{Calculations and statistics}

Due to the lack of previous data on the ratio of hepatic to portal venous bacterial counts, we did not perform sample size calculation. A predefined analysis of data was done after six animals in the naive and the SIRS groups, and three animals in the control group. The statistical analysis was planned before the experiments and 
performed accordingly. Data were tested for normality. Data with a log-normal distribution were log-transformed. All values are expressed as mean \pm SD or median (IQR) as appropriate, unless otherwise stated. For normally distributed data, Student's $t$ test was used for intergroup comparisons. ANOVA III for repeated measurements was used to assess group differences, change over time or group and time interaction, and if group differences were found, Unequal N HSD test was used as a post hoc test to identify between which groups the differences were found. For non-normally distributed data, the Mann-Whitney $U$ test was performed for intergroup comparisons. Spearman's rank correlation was calculated to test the potential associations between variables. All analyses were done using Statistica ${ }^{\text {Tm }}$ software (version 13.2, StatSoft, Inc., Tulsa, OK, USA). A $p$ value of $<0.05$ was considered statistically significant. The comparison of the control group with the SIRS group was performed in addition to the original statistical plan.

\section{Results}

Additional file 1: Table S2 summarises the piglets' characteristics at start-up. The baseline values were similar in the three groups. All animals survived throughout the experiment.

In the SIRS group, TNF- $\alpha$ and IL-6 levels peaked $2 \mathrm{~h}$ after the start of the endotoxin infusion (as a sign of SIRS). After $24 \mathrm{~h}$ of endotoxemia, i.e. at $0 \mathrm{~h}$ just before the start of bacteraemia, cardiac index (CI) was lower and arterial lactate higher. MAP was similar in the naive and SIRS group (Table 1).

\section{Hepatic bacterial elimination}

No bacteria were detected in arterial blood cultures taken at $0 \mathrm{~h}$ in the animals. The amounts of $E$. coli administered were comparable between the naive, the SIRS and the control groups $\left(8.7( \pm 0.2)\right.$ vs. $8.8( \pm 0.2)$ vs. $8.8( \pm 0.2) \log _{10}$ CFU). Figure 2 shows bacterial counts in the portal, hepatic venous and arterial blood during the bacterial infusion. The proportion of bacteria passing the liver circulation, i.e. the ratio of hepatic to portal venous bacterial counts, was lower in the naive group vs. the SIR group at $1-3 \mathrm{~h}(p=0.03)$. In addition, the ratio of arterial to portal venous bacterial counts was lower in the naive group vs. the SIR group at $1-3 \mathrm{~h}(p=0.049)$. There were no differences in bacterial counts between the control and naive group.

\section{Blood ex vivo bactericidal capacity}

The blood bactericidal capacity ex vivo is missing for two animals in the naive group due to a technical error. The bactericidal capacity (Table 2 ) was higher in the naive animals, which is seen as lower bacterial counts in the naive $(n=4)$ vs. the SIRS group $(n=6 ; p=0.001)$ and the naive $(n=4)$ vs. the control group $(n=3 ; p=0.001)$. No bacteria could be detected in the samples of the naive group after $3 \mathrm{~h}$, whereas bacterial growth was noted in the SIRS and the control group up to $6 \mathrm{~h}$.

\section{Hepatic endotoxin elimination}

Endotoxin levels were below detection limit in the portal vein and low in the hepatic vein at start-up in the naive $(0.05(0.05-0.05))$ vs. SIRS group $\left(0.05(0.05-0.13) \mathrm{EU} \times \mathrm{mL}^{-1}\right)$. 
Table 1 Physiological variables, norepinephrine dose and blood count during the experiment

\begin{tabular}{|c|c|c|c|}
\hline Variable and time (h) & Naive & SIRS & Controls \\
\hline \multicolumn{4}{|c|}{ Mean arterial pressure $(\mathrm{mmHg})$} \\
\hline-24 & & $71( \pm 6)$ & $76( \pm 13)$ \\
\hline-22 & & $84( \pm 6)$ & $75( \pm 11)$ \\
\hline-18 & & $74( \pm 9)$ & $80( \pm 14)$ \\
\hline 0 & $78( \pm 11)$ & $74( \pm 9)$ & $85( \pm 10)$ \\
\hline 1 & $77( \pm 10)$ & $78( \pm 8)^{*}$ & $80( \pm 5)$ \\
\hline 2 & $77( \pm 13)$ & $91( \pm 6)^{*}$ & $87( \pm 30)$ \\
\hline 3 & $69( \pm 11)$ & $92( \pm 7)^{*}$ & $95( \pm 24)$ \\
\hline 4 & $81( \pm 11)$ & $92( \pm 8)$ & $94( \pm 19)$ \\
\hline 5 & $76( \pm 9)$ & $88( \pm 7)$ & $77( \pm 6)$ \\
\hline 6 & $75( \pm 9)$ & $86( \pm 7)$ & $63( \pm 9)$ \\
\hline \multicolumn{4}{|c|}{ Norepinephrine dose $\left(\mu \mathrm{g} \times \mathrm{kg}^{-1} \times \mathrm{min}^{-1}\right)$} \\
\hline-24 & & $0(0-0)$ & $0(0-0.07)$ \\
\hline-22 & & $0(0-0)$ & $0(0-0.07)$ \\
\hline-18 & & $0(0-0)$ & $0.06(0-0.07)$ \\
\hline 0 & $0(0-0)$ & $0(0-0)$ & $0.06(0-0.29)$ \\
\hline 1 & $0.06(0-0.13)$ & $0(0-0)$ & $0.26(0.1-0.29)^{*}$ \\
\hline 2 & $0.03(0-0.13)$ & $0(0-0)$ & $0.26(0-0.58)$ \\
\hline 3 & $0.19(0-0.28)$ & $0(0-0)^{*}$ & $0.26(0-0.58)$ \\
\hline 4 & $0.13(0.06-0.51)$ & $0(0-0)$ & $0.26(0-0.58)$ \\
\hline 5 & $0.13(0.06-0.26)$ & $0(0-0)$ & $0.26(0-0.58)$ \\
\hline 6 & $0.13(0.06-0.14)$ & $0(0-0)$ & $0.26(0-0.58)$ \\
\hline \multicolumn{4}{|c|}{ Cardiac index $\left(L \times \min ^{-1} \times \mathrm{m}^{-2}\right)$} \\
\hline-24 & & $2.7( \pm 0.5)$ & $3.2( \pm 0.2)$ \\
\hline-22 & & $2.9( \pm 0.4)$ & $2.6( \pm 0.3)$ \\
\hline-18 & & $3.0( \pm 0.6)$ & $2.6( \pm 0.6)$ \\
\hline 0 & $2.9( \pm 0.9)$ & $3.8( \pm 0.6)$ & $3.0( \pm 0.4)$ \\
\hline 1 & $2.2( \pm 0.4)$ & $4.3( \pm 0.5)^{* * *}$ & $2.7( \pm 0.4)$ \\
\hline 2 & $2.7( \pm 1.2)$ & $3.6( \pm 0.7)^{* * *}$ & $3.5( \pm 0.6)$ \\
\hline 3 & $2.0( \pm 0.2)$ & $3.6( \pm 0.7)^{* * *}$ & $3.6( \pm 1.0)$ \\
\hline 4 & $2.0( \pm 0.5)$ & $4.0( \pm 0.7)$ & $3.6( \pm 0.7)$ \\
\hline 5 & $2.2( \pm 0.5)$ & $3.8( \pm 0.8)$ & $4.0( \pm 0.7)$ \\
\hline 6 & $2.5( \pm 0.2)$ & $4.4( \pm 0.7)$ & $4.4( \pm 0.9)$ \\
\hline \multicolumn{4}{|c|}{ Arterial lactate $\left(\mathrm{mmol} \times \mathrm{L}^{-1}\right)$} \\
\hline-24 & & $1.8( \pm 0.26)$ & $1.1( \pm 0.38)$ \\
\hline-22 & & $1.2( \pm 0.21)$ & $0.7( \pm 0.19)$ \\
\hline-18 & & $0.8( \pm 0.13)$ & $0.7( \pm 0.16)$ \\
\hline 0 & $1.2( \pm 0.37)$ & $0.8( \pm 0.16)$ & $0.8( \pm 0.11)$ \\
\hline 1 & $2.2( \pm 0.82)$ & $1.0( \pm 0.10)^{* * *}$ & $1.4( \pm 1.9)$ \\
\hline 2 & $2.2( \pm 0.27)$ & $1.2( \pm 0.21)^{* * *}$ & $1.9( \pm 0.56)$ \\
\hline 3 & $3.0( \pm 0.69)$ & $1.1( \pm 0.29)^{* * *}$ & $2.4( \pm 0.32)$ \\
\hline 4 & $2.6( \pm 1.2)$ & $1.1( \pm 0.34)$ & $1.8( \pm 0.81)$ \\
\hline 5 & $2.0( \pm 1.2)$ & $1.0( \pm 0.27)$ & $1.5( \pm 0.76)$ \\
\hline 6 & $1.4( \pm 1.1)$ & $0.9( \pm 0.19)$ & $1.3( \pm 0.81)$ \\
\hline
\end{tabular}

Values are expressed as mean $( \pm S D)$, except the norepinephrine dose that is expressed as median (IQR) Difference vs. the naive group 1-6 $\mathrm{h}$ assessed with ANOVA III for repeated measurements except for norepinephrine dose assessed with the Mann-Whitney $U$ test 


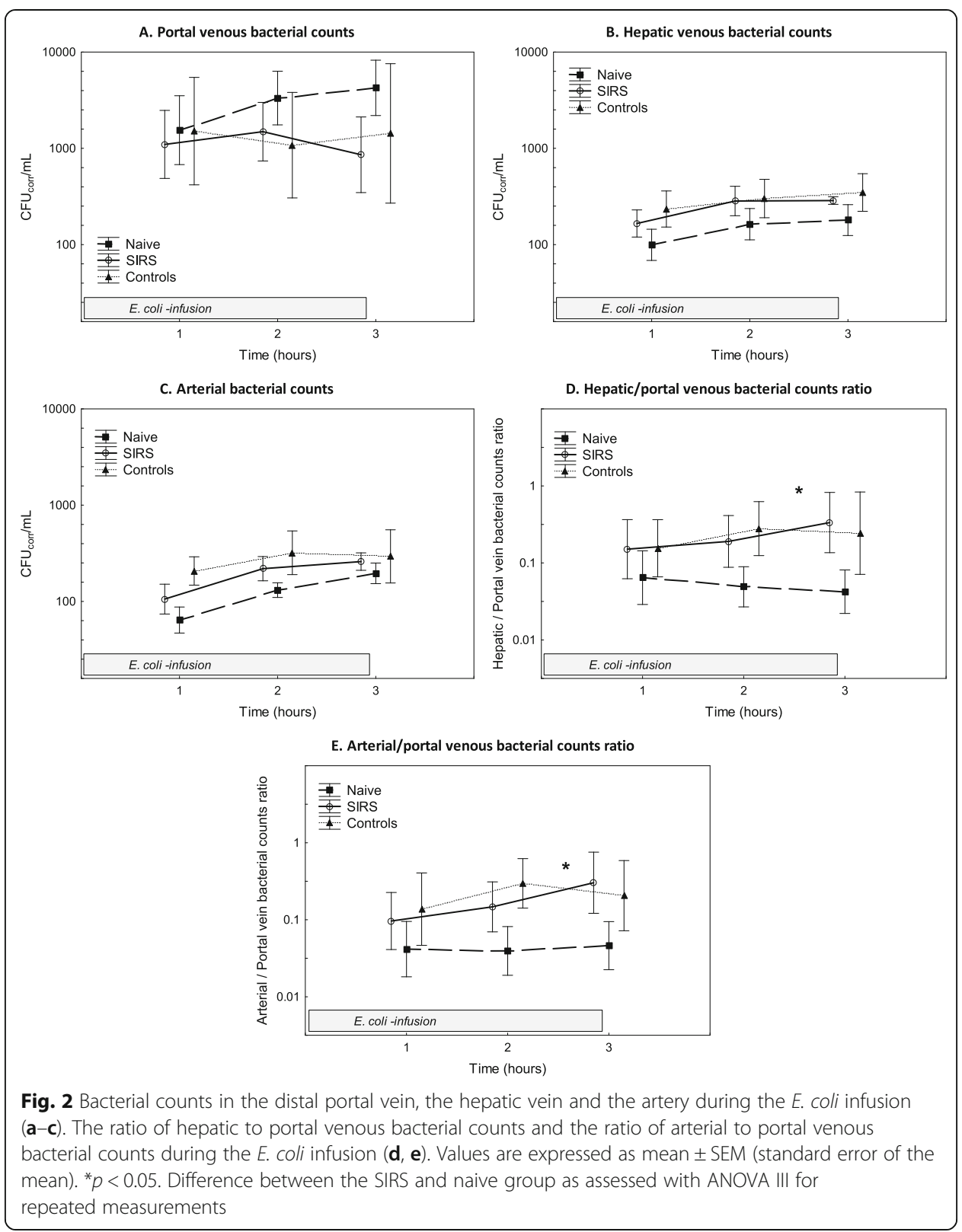

Endotoxin levels were below detection limit at both sites in the naive group at $0 \mathrm{~h}$. In the SIRS group at $0 \mathrm{~h}$, i.e. during ongoing endotoxin infusion, the endotoxin levels were below the detection limit in the portal vein and slightly elevated in the hepatic vein $\left(0.11(0.05-0.31) \mathrm{EU} \times \mathrm{mL}^{-1}\right)$. At $3 \mathrm{~h}$, just before the end of the E. coli infusion, the endotoxin levels were higher in the naive group compared with the SIRS group in the portal $(10.73(8.2-15.3)$ vs. $1.64(1.52-1.90), p=0.02)$ and the hepatic vein $\left(2.98(2.69-3.06)\right.$ vs. $\left.1.70(1.35-1.88) \mathrm{EU} \times \mathrm{mL}^{-1}, p=0.005\right)$. Moreover, the ratio of hepatic to portal venous endotoxin levels, used as a measure of hepatic endotoxin elimination, was lower in the naive group compared with the SIRS group (Fig. 3, $p=0.03$ ). There were no differences in endotoxin concentrations between the control and the naive group. The endotoxin levels in the portal vein at $3 \mathrm{~h}$ correlated with the portal venous bacterial counts $(\rho=0.73)$. 
Table 2 Bacterial counts showing blood ex vivo bactericidal capacity

\begin{tabular}{llll}
\hline Time $(h)$ & Naive group & SIRS group & Control group*** \\
\hline 0 & $5.0( \pm 0.4)$ & $4.9( \pm 0.2)$ & $4.9( \pm 0.1)$ \\
1 & $1.1( \pm 0.7)$ & $3.0( \pm 0.9)$ & $3.5( \pm 0.9)$ \\
2 & $0.0( \pm 0.0)$ & $2.4( \pm 1.3)$ & $3.4( \pm 1.1)$ \\
3 & $0.3( \pm 0.6)$ & $2.0( \pm 1.4)$ & $3.2( \pm 1.5)$ \\
4 & $0.0( \pm 0.0)$ & $1.7( \pm 1.4)$ & $2.7( \pm 2.4)$ \\
5 & $0.0( \pm 0.0)$ & $1.3( \pm 1.5)$ & $2.8( \pm 2.5)$ \\
6 & $0.0( \pm 0.0)$ & $1.2( \pm 1.4)$ & $2.9( \pm 2.7)$ \\
\hline
\end{tabular}

Values are log-transformed and expressed as mean \pm SD

Difference vs. the naive group 1-6 $\mathrm{h}$ assessed with ANOVA III for repeated measurements

${ }^{* * *} p<0.001$

\section{Inflammatory, complement and circulatory response}

The plasma TNF- $\alpha$ peaked $1 \mathrm{~h}$ after the start of the E. coli infusion while the IL-6 levels peaked $3 \mathrm{~h}$ after in both groups; the peak levels were higher in the naive group $(p<0.001)$ than in the SIRS group $(p<0.001)$ and the control group $(p<0.001 ;$ Fig. 4$)$. Similar increases in IL-10 were observed in all groups during the experiment. The IL-10/TNF- $\alpha$ ratio increased markedly in the SIRS group but decreased in the naive group during $E$. coli infusion. This pattern remained throughout the experiment $(p<0.001)$.

Unlike the naive and the control groups, the SIRS group increased in sC5-9 levels during the E. coli infusion and had higher levels than the naive group during the experiment (Fig. 5, $p<0.001$ ).

MAP was lower in the naive group compared with the SIRS group during bacterial infusion despite higher doses of norepinephrine $(p=0.01$, Table 1$)$. CI was lower and arterial lactate levels were higher during the E. coli infusion in the naive group compared with the SIRS group $(p<0.001$ for both). No difference was seen in IL-6, IL-10, IL-10/TNF- $\alpha$ ratio, MAP, arterial lactate and sC5-9 levels between the control and

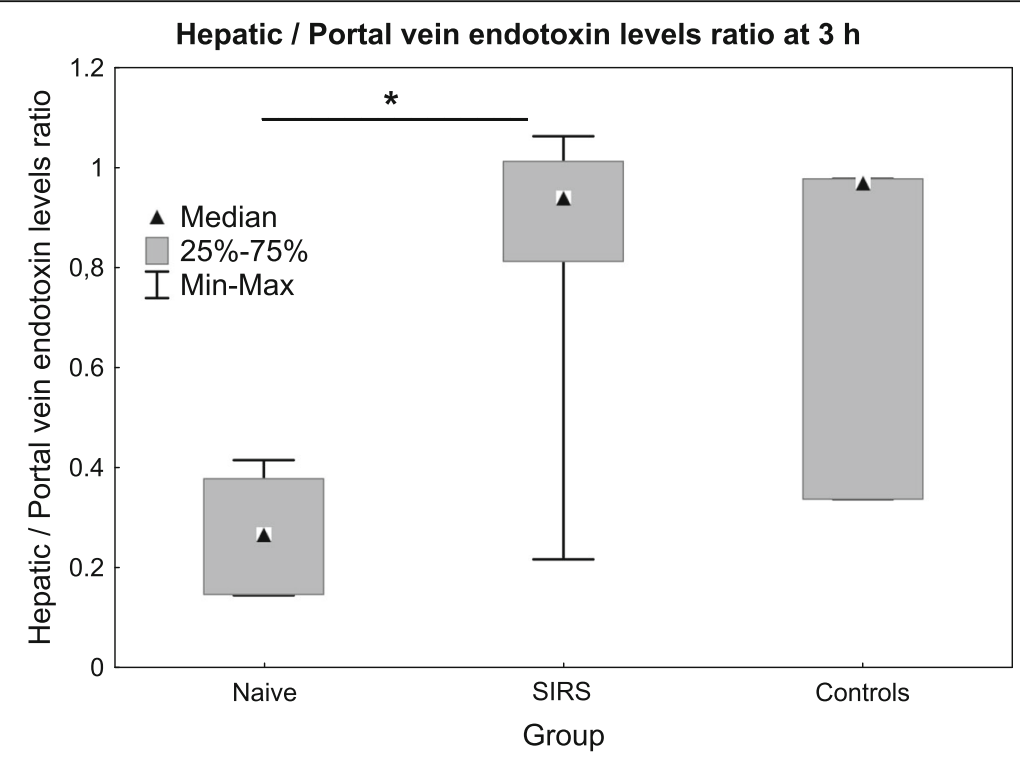

Fig. 3 The hepatic to portal venous endotoxin ratio during the E. coli infusion at $3 \mathrm{~h}$. Values are expressed as median (IQR). ${ }^{* *} p<0.001$. Difference between the SIRS and naive group as assessed with the MannWhitney $U$ test 


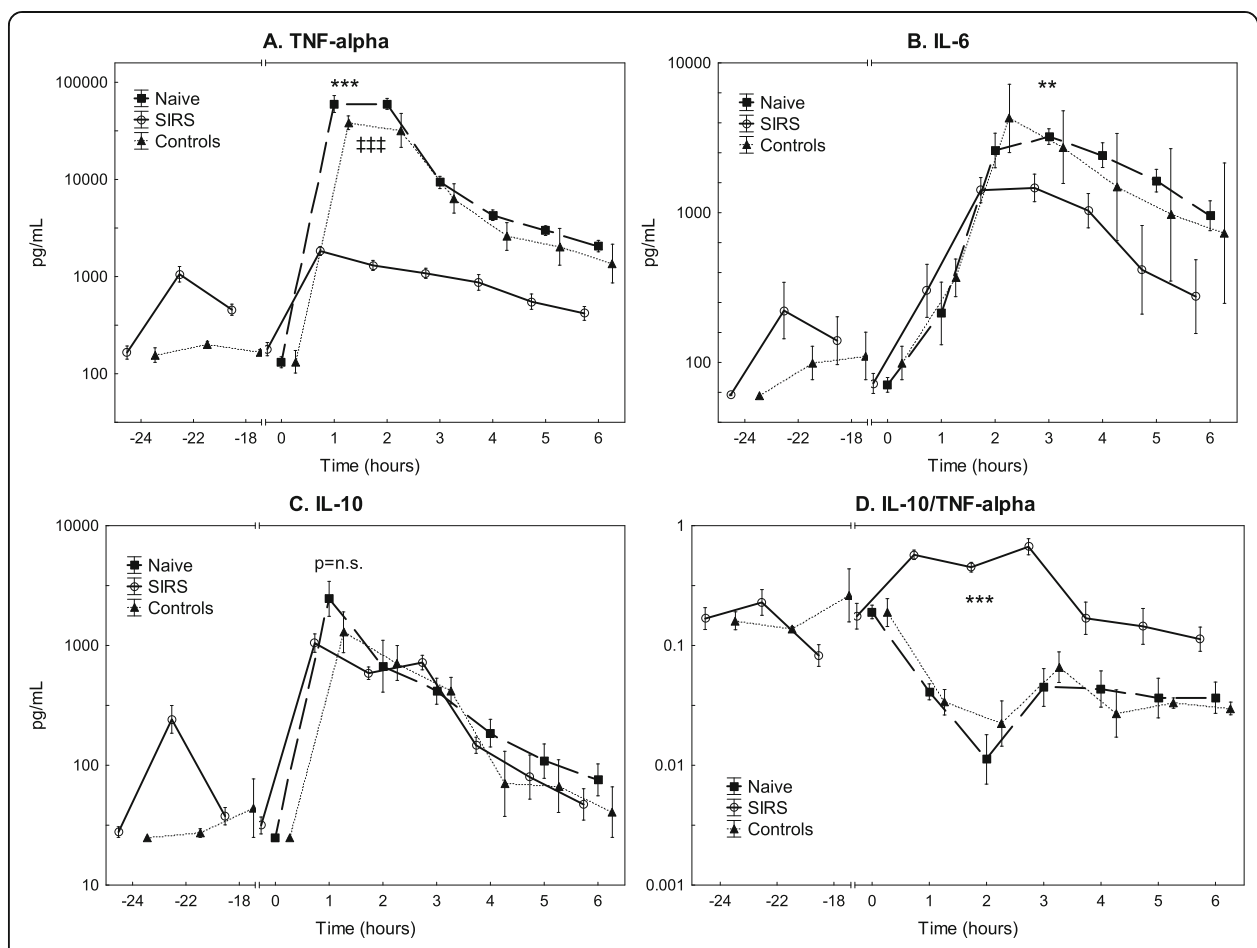

Fig. 4 The levels of tumour necrosis factor alpha (TNF-a) (a), interleukin 6 (IL-6) (b), interleukin 10 (IL-10) (c) and interleukin 10/TNF-a ratio (d) during the experiment. All animals were subjected to an E. coli infusion for $3 \mathrm{~h}$ starting at $0 \mathrm{~h}$. The SIRS group received endotoxin and the control group saline for $24 \mathrm{~h}$ before the bacterial infusion. Values are expressed as mean \pm SEM (standard error of the mean). ${ }^{* *} p<0.01,{ }^{* *} p<0.001$. Difference between the SIRS vs. naive group. ${ }^{\neq \neq \neq} p<0.001$. Difference between the control vs. naive group. All assessed with ANOVA III for repeated measurements

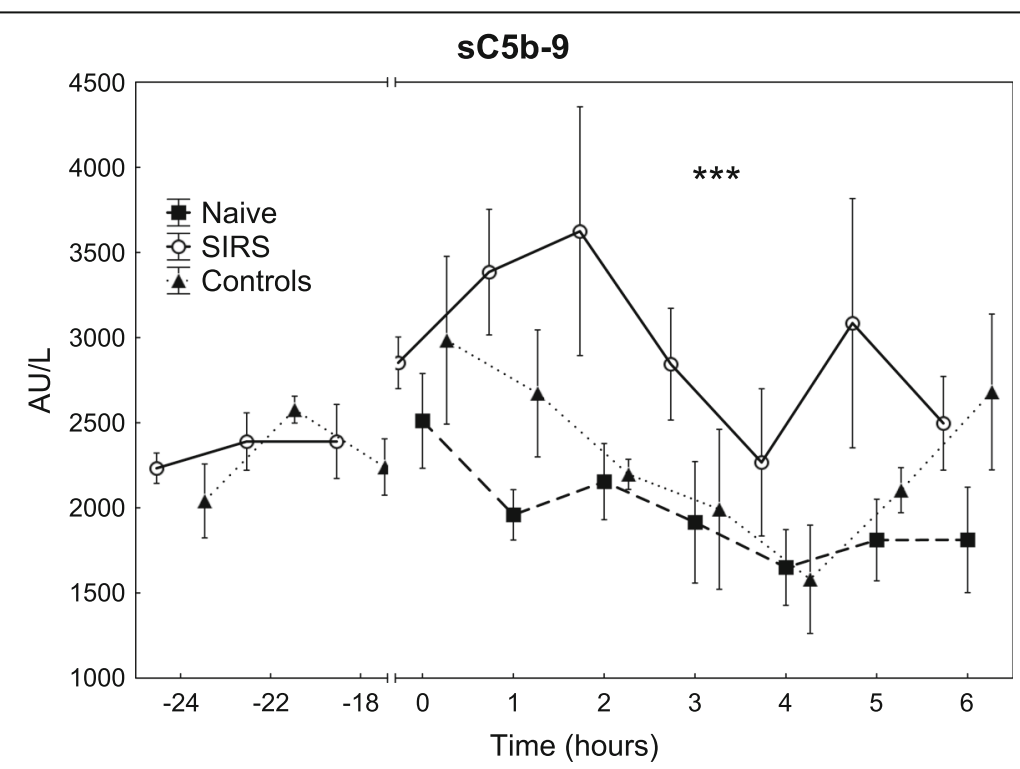

Fig. 5 The levels of complement activation measured as sC5-9 during the experiment. All animals were subjected to an E. coli infusion for $3 \mathrm{~h}$ starting at $0 \mathrm{~h}$. The SIRS group received endotoxin and the control group saline for $24 \mathrm{~h}$ before the bacterial infusion. Values are expressed as mean \pm SEM (standard error of the mean). ${ }^{* * *} p<0.001$. Difference between the SIRS and naive group as assessed with ANOVA III for repeated measurements 
naive group. TNF- $\alpha$ was lower and the dose of noradrenalin were higher in the control group compared with the naive group during the experiment.

\section{Estimation of liver function with indocyanine green}

There was no difference in ICG-PDR between the naive and SIRS group at start-up (18.6 $( \pm 6.4)$ vs. $21.4( \pm 5.0)$, percent per minute). ICG-PDR was lower in the naive vs. the SIRS group $(18.6( \pm 6.4)$ vs. $32.4( \pm 8.7)$, percent per minute, $p=0.02)$ at $0 \mathrm{~h}$. No differences were seen between the control and naive group.

\section{Discussion}

\section{Key findings}

Hepatic bacterial elimination is very efficient in healthy animals but markedly impaired by even mild systemic inflammation. Likewise, endotoxin elimination by the liver is decreased in pigs with an ongoing systemic inflammatory response. Moreover, the bacterial killing capacity of the blood was notably reduced by mild systemic inflammation. The inflammatory response to an E. coli infusion, measured as peak levels of TNF- $\alpha$ and IL-6, was attenuated and showed an anti-inflammatory predominance measured as IL-10/TNF- $\alpha$ ratio, in pigs with relatively mild pre-existing systemic inflammation.

\section{Previous studies}

The effects of inflammation-induced immunosuppression on bacterial elimination have previously been studied but with ambiguities and conflicting results. Preconditioning with endotoxin has been associated with augmented bacterial elimination from the circulation [29-31] and even with increased survival [29, 31]. The increased bacterial clearance after previous endotoxin challenge seen in these studies [29-31] seems to contradict our results. However, the immunological response after endotoxin preconditioning is dependent on the magnitude of the initial endotoxin challenge [32]. Moreover, timing of the secondary insult after the endotoxin challenge is a key factor in outcome [33] given that endotoxin tolerance diminishes over time. The high IL-10/TNF- $\alpha$ ratio in the animals pre-exposed to endotoxin in our study suggests that these animals were still in an IL-10dominant immunosuppressed state. This is in line with the finding that IL-10 has been shown to mediate decreased bacterial clearance [30]. A study on isolated rat livers also demonstrated increased bacterial elimination and increased destruction of phagocytised bacteria after induction of systemic inflammation [34]. On the other hand, reduced bacterial clearance from blood and increased growth of bacteria in organs, including the liver, were reported in rabbits pre-exposed to endotoxin [35]. This study used intravenous infusion of bacteria, similarly to our report, that induces a more acute immune activation and may result in decreased bacterial clearance. Thus, the characteristics of both the primary and secondary insult seemingly affect bacterial clearance. In the present study focusing on hepatic elimination, we observed decreased elimination of $E$. coli by the liver in mild systemic inflammation. Both the degree and the duration of systemic inflammation before bacteraemia may be of importance, as delayed bacterial elimination, associated with increased growth of viable bacteria in organs, was more pronounced the longer the duration of systemic inflammation [35]. Furthermore, the effects of systemic inflammation 
on bacterial elimination may vary between organs. Our study specifically investigated hepatic bacterial elimination by the liver during pre-existing systemic inflammation.

The mechanisms underlying decreased bacterial elimination by the liver in systemic inflammation seen in our study are unclear. Several mechanisms in the liver are affected by sepsis [36]. In mice, hepatic bacterial clearance decreased during severe bacteraemia and mild bacteraemia developed into severe bacteraemia with increased mortality in the setting of Kupffer cell ablation. Similarly to our findings, decreased Kupffer cell function has been associated with increased systemic endotoxemia [37]. These findings illustrate the importance of these resident macrophages for bacterial elimination and that decreased hepatic bacterial elimination can affect outcome in bacteraemia [38]. We assessed liver function by ICG clearance [28], finding no signs of decreased liver function in animals exposed to endotoxin compared with the previously healthy ones before the E. coli infusion was started. This finding suggests that decreased hepatic bacterial elimination during systemic inflammation is most likely not explained by liver failure.

Hepatic endotoxin elimination was also decreased during E. coli bacteraemia in pigs with pre-existing systemic inflammation, corresponding to previous findings in mice hepatocytes [39]. Conversely, increased endotoxin clearance was reported after induction of endotoxin tolerance in rats [40]. Because we investigated global hepatic endotoxin elimination, the mechanisms underlying our findings are unclear. We demonstrated that pig blood is bactericidal on its own and contributes to total bacterial clearance. This bactericidal capacity was decreased in pigs with pre-existing systemic inflammation compared to healthy animals. Rapid killing of E. coli in the circulation and subsequent release of endotoxin may account for the high endotoxin levels measured in portal venous blood in the healthy animals with a high bacterial killing rate.

The differences in bacterial killing rate in blood between the groups are not explained fully by our findings. sC5-9 levels increased in the SIRS group and decreased in the naive group and were higher in the former group during bacteraemia. Since sC5-9 is essential for bacterial killing in blood [41], it is therefore unlikely that complement activation explains the observed decrease in bacterial elimination both in vivo and ex vivo in the SIRS group.

The physiological and inflammatory response to the bacterial infusion was diminished in pigs with pre-existing systemic inflammation, as manifested by only subtle changes in arterial blood pressure, arterial lactate and TNF- $\alpha$ levels. In contrast, healthy animals developed hypotension requiring noradrenalin treatment according to the protocol, hyperlactatemia and increased TNF- $\alpha$ levels. Although removal of bacteria and endotoxin by the liver was impaired in animals with pre-existing systemic inflammation, possibly leading to an increased systemic PAMPs load, it did not elicit an augmented inflammatory response in these animals. In this study, we found a substantially reduced bacterial killing capacity in the blood after endotoxin exposure for $24 \mathrm{~h}$ that corresponds to our previous finding that the inflammatory response of leukocytes to endotoxin is reduced [33]. Similar mechanisms may prevail in the phagocytic cells and neutrophils of the liver [42]. The reduced ability of the liver to eliminate bacteria and endotoxin during ongoing systemic inflammation, leading to increased inflow of these into the systemic circulation combined with a diminished physiological, inflammatory and metabolic response, could imply that the capability of the body to isolate and respond to abdominal bacterial infections is impaired in this condition. 
This contention could be of clinical relevance seeing that the association between an inflammation-induced decrease in phagocytic cell function and the increased risk of organ failure has been described in trauma patients [43]. Decreased elimination of PAMPs by the liver and the lower bactericidal capacity of the blood during systemic inflammation could also be phenomena consistent with sepsis-induced immunosuppression.

\section{Strengths and limitations}

To our knowledge, this is the first study to evaluate the effects of systemic inflammation on bacterial elimination by the liver in vivo, as well as the first to describe diminished hepatic endotoxin elimination during systemic inflammation in a large animal model. The juvenile pig is large enough to allow instrumentation and monitoring used in intensive care units, making our model more clinically relevant than small animal models. Because organ support in itself affects the inflammatory response [44, 45], using an intensive care model also increases the clinical relevance of our study. Additionally, the porcine liver has similar anatomical, physiological and immunological properties as the human liver [46], and the circulation of the pig has been suggested to be most similar to that of humans among non-primates $[47,48]$. Finally, we had a control group to describe the effects of 24 $\mathrm{h}$ of anaesthesia. The control group was similar to the naive group in most aspects; however, lower TNF- $\alpha$ levels and blood bactericidal capacity as well as a more hyperdynamic circulatory response to the $E$. coli infusion were seen in this group. Thus, the inherent effects of $24 \mathrm{~h}$ of anaesthesia were limited.

The study has several limitations. We conclude that bacterial elimination by the liver is impaired by systemic inflammation, but because no liver biopsies for cultures were taken, the bacterial killing capacity of the liver was not assessed. Because the concentration of bacteria in our samples is dependent on blood flow in both the portal vein and the hepatic artery, changes in the splanchnic blood flow could, in theory, have affected our results. Blood flow to the liver was not measured because in the pilot phase of the study instrumentation of the portal vein and hepatic artery to attach flow probes led to transient hepatic circulation impairments that could have affected bacterial elimination. However, given the magnitude of change in hepatic bacterial and endotoxin elimination, it is highly unlikely that our results depend on changes in hepatic blood flow.

\section{Clinical implications}

Our data suggest that hepatic bacterial and PAMP eliminations are very efficient under healthy conditions, but even mild systemic inflammation could lead to increased inflow of bacteria and PAMPs into the systemic circulation. Concurrently, the ongoing SIRS limits the inflammatory, physiological and metabolic response of the body to these microbial triggers making it particularly vulnerable to microbial invasion. Moreover, these results imply that the microbial filter function of the liver fails in systemic inflammation, and that microbial spread via the splanchnic blood flow that in health would be eliminated by the hepatic MPS could enter the systemic circulation in severe illness and sustain systemic inflammation. Future therapeutic approaches to prevent or treat decreased hepatic elimination of PAMPs could be a novel way to tackle immunoparalysis in sepsis. 


\title{
Conclusions
}

Hepatic bacterial and endotoxin elimination is impaired by a systemic inflammatory response, and the physiological and inflammatory responses to bacteraemia are diminished in pigs with ongoing systemic inflammation. If similar mechanisms operate in the human inflammatory response, the hepatic bacterial elimination is impaired by systemic inflammation, allowing enteric bacteria to escape into the systemic circulation. Future studies should explore the cellular mechanisms of deceased hepatic bacterial and endotoxin elimination.

\section{Additional file}

Additional file 1: Supplement file. Table S1. Experimental protocol. Table S2. Animals' weight and physiological variables at start up. (DOCX $24 \mathrm{~kb})$

\begin{abstract}
Abbreviations
ARRIVE: ARRIVE guidelines; CFU: Colony forming units; Cl: Cardiac index; CO: Cardiac output; E. coli: Escherichia coli; ICG: Indocyanine green; ICG-PDR: Indocyanine green plasma disappearance rate; IL-10: Interleukin 10; IL-6: Interleukin 6; MAP: Mean arterial pressure; MODS: Multiple organ dysfunction syndrome; MPS: Mononuclear phagocyte system; PAMP: Pathogen-associated molecular pattern; $\mathrm{PaO}_{2}$ : Arterial pressure of oxygen; SIRS: Systemic inflammatory response syndrome; Soluble TCC (sC5b-9): Soluble terminal complement complex (sC5b-9); TNF-a: Tumour necrosis alpha
\end{abstract}

\section{Acknowledgements}

Kerstin Ahlgren, Monika Hall, Anders Nordgren, Agneta Roneus and Maria Swälas at the Hedenstierna Laboratory are greatly acknowledged for excellent support. Charlotte Annerstedt and Stina Vincentsson are acknowledged for providing outstanding laboratory assistance.

\section{Authors' contributions}

$\mathrm{ML}, \mathrm{KH}$ and JS conceived the study. All authors contributed to the experimental design. The experiments were performed by KH, PS, FW and ML. Laboratory analyses were mainly done by AL and ET. Data analysis was performed by $\mathrm{KH}$ and $\mathrm{ML}$. The manuscript was drafted by $\mathrm{KH}$ and $\mathrm{ML}$ with all authors contributing to the final version. All authors read and approved the final manuscript.

\section{Funding}

This work was supported by the SwedishSsociety of Medicine (SLS-409831), the Uppsala University Hospital Research Fund and the Olinder-Nielsen foundation.

\section{Availability of data and materials}

The datasets used and/or analysed during the current study are available from the corresponding author on reasonable request.

\section{Ethics approval and consent to participate}

The experiment was approved by the Animal Ethics Board in Uppsala, Sweden (No. C150/14). The piglets were handled in accordance with the Guide for the Care and Use of Laboratory Animals (EU Directive 2010/63/EU).

\section{Consent for publication}

Not applicable.

\section{Competing interests}

The authors declare that they have no competing interests.

\section{Author details}

${ }^{1}$ Anesthesiology and Intensive Care, Department of Surgical Sciences, Uppsala University, Uppsala, Sweden. ${ }^{2}$ Section of Infectious Diseases, Department of Medical Sciences, Uppsala University, Uppsala, Sweden. ${ }^{3}$ Hedenstierna Laboratory, CIRRUS, Anesthesiology and Intensive Care, Department of Surgical Sciences, Uppsala University, Uppsala, Sweden. ${ }^{4}$ Section of Clinical Chemistry, Department of Medical Sciences, Uppsala University, Uppsala, Sweden. ${ }^{5}$ Perioperative Medicine and Intensive Care, Karolinska University Hospital and CLINTEC, Karolinska Institute, Stockholm, Sweden. ${ }^{6}$ Section of Clinical Bacteriology, Department of Medical Sciences, Uppsala University, Uppsala, Sweden.

Received: 30 March 2019 Accepted: 19 August 2019

Published online: 27 August 2019

\section{References}

1. Lynch SV, Pedersen O (2016) The human intestinal microbiome in health and disease. The New England journal of medicine 375:2369-2379 
2. Balmer ML, Slack E, de Gottardi A, Lawson MA, Hapfelmeier S, Miele L, Grieco A, Van Vlierberghe H, Fahrner R, Patuto N, Bernsmeier C, Ronchi F, Wyss M, Stroka D, Dickgreber N, Heim MH, McCoy KD, Macpherson AJ (2014) The liver may act as a firewall mediating mutualism between the host and its gut commensal microbiota. Science translational medicine 6:237ra266

3. Benacerraf B, Sebestyen MM, Schlossman S (1959) A quantitative study of the kinetics of blood clearance of P32-labelled Escherichia coli and Staphylococci by the reticuloendothelial system. The Journal of experimental medicine 110:27-48

4. Berg RD, Garlington AW (1979) Translocation of certain indigenous bacteria from the gastrointestinal tract to the mesenteric lymph nodes and other organs in a gnotobiotic mouse model. Infection and immunity 23:403-411

5. Deitch EA (2010) Gut lymph and lymphatics: a source of factors leading to organ injury and dysfunction. Annals of the New York Academy of Sciences 1207 Suppl 1:E103-E111

6. MacFie J (2004) Current status of bacterial translocation as a cause of surgical sepsis. British medical bulletin 71:1-11

7. O'Boyle C, MacFie J, Mitchell C, Johnstone D, Sagar P, Sedman P (1998) Microbiology of bacterial translocation in humans. Gut 42:29-35

8. Cirera I, Bauer TM, Navasa M, Vila J, Grande L, Taura P, Fuster J, Garcia-Valdecasas JC, Lacy A, Suarez MJ, Rimola A, Rodes J (2001) Bacterial translocation of enteric organisms in patients with cirrhosis. J Hepatol 34:32-37

9. Deitch EA (1989) Simple intestinal obstruction causes bacterial translocation in man. Archives of surgery (Chicago, III : 1960) 124:699-701

10. MacFie J, O'Boyle C, Mitchell CJ, Buckley PM, Johnstone D, Sudworth P (1999) Gut origin of sepsis: a prospective study investigating associations between bacterial translocation, gastric microflora, and septic morbidity. Gut 45:223-228

11. MacFie J, Reddy BS, Gatt M, Jain PK, Sowdi R, Mitchell CJ (2006) Bacterial translocation studied in 927 patients over 13 years. Br J Surg 93:87-93

12. Schietroma M, Pessia B, Carlei F, Mariani P, Sista F, Amicucci G (2016) Intestinal permeability and systemic endotoxemia in patients with acute pancreatitis. Ann Ital Chir 87:138-144

13. Doig CJ, Sutherland LR, Sandham JD, Fick GH, Verhoef M, Meddings JB (1998) Increased intestinal permeability is associated with the development of multiple organ dysfunction syndrome in critically ill ICU patients. Am J Respir Crit Care Med 158:444-451

14. Falkowski NR, Branton W, Younger JG, Puskarich MA, Jones AE, Stringer KA, Dickson RP (2018) Evidence of gut translocation in sepsis: burden and diversity of bacterial DNA in blood predicts organ failure in septic patients. American Journal of Respiratory and Critical Care Medicine 197:A4179-A4179

15. Hotchkiss RS, Tinsley KW, Swanson PE, Schmieg RE Jr, Hui JJ, Chang KC, Osborne DF, Freeman BD, Cobb JP, Buchman TG, Karl IE (2001) Sepsis-induced apoptosis causes progressive profound depletion of B and CD4+ T lymphocytes in humans. Journal of immunology (Baltimore, Md : 1950) 166:6952-6963

16. Hotchkiss RS, Karl IE (2003) The pathophysiology and treatment of sepsis. The New England journal of medicine 348:138-150

17. Heidecke C-D, Hensler T, Weighardt H, Zantl N, Wagner H, Siewert J-R, Holzmann B (1999) Selective defects of T lymphocyte function in patients with lethal intraabdominal infection. The American Journal of Surgery 178:288-292

18. Amatullah H, Shan Y, Beauchamp BL, Gali PL, Gupta S, Maron-Gutierrez T, Speck ER, Fox-Robichaud AE, Tsang JL, Mei SH, Mak TW, Rocco PR, Semple JW, Zhang H, Hu P, Marshall JC, Stewart DJ, Harper ME, Liaw PC, Liles WC, Dos Santos CC, Canadian Critical Care Translational Biology G (2017) DJ-1/PARK7 impairs bacterial clearance in sepsis. Am J Respir Crit Care Med 195:889-905

19. Gogos CA, Drosou E, Bassaris HP, Skoutelis A (2000) Pro- versus anti-inflammatory cytokine profile in patients with severe sepsis: a marker for prognosis and future therapeutic options. J Infect Dis 181:176-180

20. Osuchowski MF, Ayala A, Bahrami S, Bauer M, Boros M, Cavaillon JM, Chaudry IH, Coopersmith CM, Deutschman C, Drechsler S, Efron P, Frostell C, Fritsch G, Gozdzik W, Hellman J, Huber-Lang M, Inoue S, Knapp S, Kozlov AV, Libert C, Marshall JC, Moldawer LL, Radermacher P, Redl H, Remick DG, Singer M, Thiemermann C, Wang P, Wiersinga WJ, Xiao X, Zingarelli B (2018) Minimum quality threshold in pre-clinical sepsis studies (MQTiPSS): an international expert consensus initiative for improvement of animal modeling in sepsis. Intensive Care Med Exp 6:26

21. Kilkenny C, Browne WJ, Cuthill IC, Emerson M, Altman DG (2010) Improving bioscience research reporting: the ARRIVE guidelines for reporting animal research. PLoS Biol 8:e1000412

22. Castegren M, Lipcsey M, Soderberg E, Skorup P, Eriksson M, Larsson A, Sjolin J (2012) Differences in organ dysfunction in endotoxin-tolerant pigs under intensive care exposed to a second hit of endotoxin. Shock 37:501-510

23. Skorup P, Maudsdotter L, Lipcsey M, Castegren M, Larsson A, Jonsson AB, Sjolin J (2014) Beneficial antimicrobial effect of the addition of an aminoglycoside to a beta-lactam antibiotic in an E. coli porcine intensive care severe sepsis model. PLoS One 9:e90441

24. Lipcsey M, Larsson A, Eriksson MB, Sjolin J (2006) Inflammatory, coagulatory and circulatory responses to logarithmic increases in the endotoxin dose in the anaesthetised pig. J Endotoxin Res 12:99-112

25. Bergquist M, Hastbacka J, Glaumann C, Freden F, Huss F, Lipcsey M (2019) The time-course of the inflammatory response to major burn injury and its relation to organ failure and outcome. Burns 45:354-363

26. Oh TE (1997) Intensive care manual. Butterworth-Heinemann, Oxford

27. Bergseth G, Ludviksen JK, Kirschfink M, Giclas PC, Nilsson B, Mollnes TE (2013) An international serum standard for application in assays to detect human complement activation products. Mol Immunol 56:232-239

28. Halle BM, Poulsen TD, Pedersen HP (2014) Indocyanine green plasma disappearance rate as dynamic liver function test in critically ill patients. Acta anaesthesiologica Scandinavica 58:1214-1219

29. Murphey ED, Fang G, Varma TK, Sherwood ER (2007) Improved bacterial clearance and decreased mortality can be induced by LPS tolerance and is not dependent upon IFN-gamma. Shock 27:289-295

30. Varma TK, Durham M, Murphey ED, Cui W, Huang Z, Lin CY, Toliver-Kinsky T, Sherwood ER (2005) Endotoxin priming improves clearance of Pseudomonas aeruginosa in wild-type and interleukin-10 knockout mice. Infect Immun 73:7340-7347

31. Wheeler DS, Lahni PM, Denenberg AG, Poynter SE, Wong HR, Cook JA, Zingarelli B (2008) Induction of endotoxin tolerance enhances bacterial clearance and survival in murine polymicrobial sepsis. Shock 30:267-273

32. Chen K, Geng S, Yuan R, Diao N, Upchurch Z, Li L (2015) Super-low dose endotoxin pre-conditioning exacerbates sepsis mortality. EBioMedicine 2:324-333

33. Castegren M, Skorup P, Lipcsey M, Larsson A, Sjolin J (2013) Endotoxin tolerance variation over $24 \mathrm{~h}$ during porcine endotoxemia: association with changes in circulation and organ dysfunction. PLoS One 8:e53221 
34. Ruggiero G, Andreana A, Utili R, Galante D (1980) Enhanced phagocytosis and bactericidal activity of hepatic reticuloendothelial system during endotoxin tolerance. Infection and immunity 27:798-803

35. Koch T, Duncker HP, Axt R, Schiefer HG, van Ackern K, Neuhof H (1993) Alterations of bacterial clearance induced by endotoxin and tumor necrosis factor. Infection and immunity 61:3143-3148

36. Strnad P, Tacke F, Koch A, Trautwein C (2016) Liver — guardian, modifier and target of sepsis. Nature Reviews Gastroenterology \&Amp; Hepatology 14:55

37. Xu CP, Liu J, Liu JC, Han DW, Zhang Y, Zhao YC (2007) Dynamic changes and mechanism of intestinal endotoxemia in partially hepatectomized rats. World J Gastroenterol 13:3592-3597

38. Ashare A, Monick MM, Powers LS, Yarovinsky T, Hunninghake GW (2006) Severe bacteremia results in a loss of hepatic bacterial clearance. American Journal of Respiratory and Critical Care Medicine 173:644-652

39. Scott MJ, Liu S, Shapiro RA, Vodovotz Y, Billiar TR (2009) Endotoxin uptake in mouse liver is blocked by endotoxin pretreatment through a suppressor of cytokine signaling-1-dependent mechanism. Hepatology (Baltimore, Md) 49:1695-1708

40. Yamaguchi Y, Mori K, Gans H, Akagi M (1986) Enhanced endotoxin clearance in reversed Eck fistula rats during a tolerant stage. The Japanese journal of surgery 16:209-217

41. Sprong T, Brandtzaeg P, Fung M, Pharo AM, Hoiby EA, Michaelsen TE, Aase A, van der Meer JW, van Deuren M, Mollnes TE (2003) Inhibition of C5a-induced inflammation with preserved C5b-9-mediated bactericidal activity in a human whole blood model of meningococcal sepsis. Blood 102:3702-3710

42. Fang CW, Yao YM, Shi ZG, Yu Y, Wu Y, Lu LR, Sheng ZY (2002) Lipopolysaccharide-binding protein and lipopolysaccharide receptor CD14 gene expression after thermal injury and its potential mechanism(s). J Trauma 53:957-967

43. Kirchhoff C, Biberthaler P, Mutschler WE, Faist E, Jochum M, Zedler S (2009) Early down-regulation of the proinflammatory potential of monocytes is correlated to organ dysfunction in patients after severe multiple injury: a cohort study. Crit Care 13:R88

44. Stolk RF, van der Poll T, Angus DC, van der Hoeven JG, Pickkers P, Kox M (2016) Potentially inadvertent immunomodulation: norepinephrine use in sepsis. Am J Respir Crit Care Med 194:550-558

45. Poll T, Jansen J, Endert E, Sauerwein HP, Deventer SJ (1994) Noradrenaline inhibits lipopolysaccharide-induced tumor necrosis factor and interleukin 6 production in human whole blood. Infection and immunity 62:2046-2050

46. Ekser B, Gridelli B, Veroux M, Cooper DK (2011) Clinical pig liver xenotransplantation: how far do we have to go? Xenotransplantation 18:158-167

47. Dodds WJ, Abelseth MK (1980) Criteria for selecting the animal to meet the research need. Lab Anim Sci 30:460-465

48. Redl H, Bahrami S, Schlag G, Traber DL (1993) Clinical detection of LPS and animal models of endotoxemia. Immunobiology 187:330-345

\section{Publisher's Note}

Springer Nature remains neutral with regard to jurisdictional claims in published maps and institutional affiliations.

\section{Submit your manuscript to a SpringerOpen ${ }^{\circ}$ journal and benefit from:}

- Convenient online submission

- Rigorous peer review

- Open access: articles freely available online

- High visibility within the field

- Retaining the copyright to your article

Submit your next manuscript at $\boldsymbol{s p r i n g e r o p e n . c o m ~}$ 